\title{
中国戈壁针茅草原的分布、群落特征和分类
}

\author{
朱媛君 ${ }^{1,2}$ 乔鲜果 ${ }^{3,4}$ 郭 柯 ${ }^{3,4}$ 旭 $日^{1}$ 赵利清 $1^{*}$ \\ ${ }^{1}$ 内蒙古大学生态与环境学院, 呼和浩特 $010021 ;{ }^{2}$ 中国林业科学研究院荒漠化研究所, 北京 $100091 ;{ }^{3}$ 中国科学院植物研究所植被与环境变化国家重 \\ 点实验室, 北京 $100093 ;{ }^{4}$ 中国科学院大学, 北京 100049
}

摘 要 戈壁针茅(Stipa tianschanica var. gobica)草原主要分布于荒漠草原区的石质丘陵或石质山坡, 向东可以分布在典型 草原区的石质丘陵或山地，向西也可以分布在荒漠区的石质山坡上。该研究调查了中国戈壁针茅草原的主要植被类型，通过 对115个样地的样方数据分析, 量化描述了这一草原类型的主要植物群落特征。结果表明, 中国戈壁针茅草原共有维管植物 272种, 隶属于 38 科 127 属; 其中裸子植物 3 种, 隶属于 1 科 1 属; 被子植物 269 种, 隶属于 37 科 126 属, 物种数大于等于 10 种的科 为: 菊科、禾本科、豆科、蓄薇科、百合科、藜科、石竹科; 戈壁针茅草原植物区系的生活型谱以地面芽植物为主, 共178 种植物, 占总种数的 $65.44 \%$; 水分生态类型以旱生植物为主, 共 120 种, 占总种数的 $44.12 \%$; 植物区系地理成分上以东古北极 分布种和亚洲中部分布种(含其变型)最多, 分别为 82 种和 80 种, 占总种数的 $30.14 \%$ 和 $29.41 \%$; 盖度等级划分上以 $0.1 \%-1.0 \%$ 的盖度最多, 共 174 种, 占总种数的 $63.97 \%$; 恒有度等级划分上以I级 $(0-20 \%)$ 的物种数最多, 共 258 种植物, 占所有植物种数 的94.85\%。基于群落调查数据, 按照群落-外貌分类原则, 将戈壁针茅群系划分为8个群从组106个群从。

关键词 群落特征; 内蒙古高原; 区系地理成分; 生态特征; 戈壁针茅

朱媛君, 乔鲜果, 郭柯, 旭日, 赵利清 (2018). 中国戈壁针茅草原的分布、群落特征和分类. 植物生态学报, 42, 785-792. DOI: 10.17521/cjpe.2017.0314

\section{Distribution, community characteristics and classification of Stipa tianschanica var. gobica steppe in China}

\author{
ZHU Yuan-Jun ${ }^{1,2}$, QIAO Xian-Guo ${ }^{3,4}$, GUO Ke ${ }^{3,4}, \mathrm{XU} \mathrm{Ri}^{1}$, and ZHAO Li-Qing ${ }^{1 *}$ \\ ${ }^{1}$ College of Ecology and Environment, Inner Mongolia University, Hohhot 010021, China; ${ }^{2}$ Institution of Desertification Studies, Chinese Academy of Forestry, \\ Beijing 100091, China; ${ }^{3}$ State Key Laboratory of Vegetation and Environmental Change, Institute of Botany, Chinese Academy of Sciences, Beijing 100093, \\ China; and ${ }^{4}$ University of Chinese Academy of Sciences, Beijing 100049, China
}

\begin{abstract}
Aims Stipa tianschanica var. gobica steppe is mainly distributed on the rocky slopes or rocky hills of desert steppe region, and can also be found in rocky hills or mountains of the typical steppe area eastwardly and some rocky slopes of the desert region westwardly. The main vegetation types of S. tianschanica var. gobica steppe in China were investigated in this paper, and based on the 115 plot samples, the characteristics of the main desert steppe plant communities from the main vegetation types were quantitatively described. And the results showed that: according to the quadrat data, 272 seed plants belonging to 38 families and 127 genera (including the subspecies, varieties and forms) were recorded in the S. tianschanica var. gobica steppe of China, among which there were 3 gymnosperm species belonging to 1 families and 1 genera, and 269 angiosperm species belonging to 37 families and 126 genera. The families having more than 10 species were Compositae, Poaceae, Leguminosae, Rosaceae, Liliaceae, Chenopodiaceae and Caryophyllaceae respectively. Hemicryptophyte, with a total of 178 species is the dominant life form in S. tianschanica var. gobica steppe, which accounted for $65.44 \%$ of the total species. As for the ecological type of water, xerophytes was the dominant plants, with a total of 120 species, accounting for $44.12 \%$ of all species. East Palaeo-North element areal-type (including 82 species) and Middle Asia element (included the variants) areal-type (including 80 species) were the major floristic elements, containing $30.14 \%$ and $29.41 \%$ of the total species. The coverage of $0.1 \%-1 \%$ was the dominant level in the cover class distribution of the species, including $63.97 \%$ of the total species. The constancy degree of I (0-20\%) was the dominant level in the constancy degree distribution of the species in S. tianschanica var. gobica steppe, containing
\end{abstract}

收稿日期Received: 2017-12-01 接受日期Accepted: 2018-05-28

基金项目：国家科技基础性工作专项重点专项(2015FY210200)和国家自然科学基金(31670532)。Supported by the National Special Program on Basic Works for Science and Technology of China (2015FY210200), and the National Natural Science Foundation of China (31670532).

* 通信作者Corresponding author (zhaotieniu@126.com) 
$94.85 \%$ of all the species. In accordance with the classification principle of community-appearance, Form. $S$. tianschanica var. gobica was divided into 8 S. tianschanica var. gobica steppe association groups, and 106 associations were divided from these 8 association groups based on community survey data.

Key words community characteristics; Nei Mongol Plateau; floristic geographic element; ecological characteristics; Stipa tianschanica var. gobica

Zhu YJ, Qiao XG, Guo K, Xu R, Zhao LQ (2018). Distribution, community characteristics and classification of Stipa tianschanica var. gobica steppe in China. Chinese Journal of Plant Ecology, 42, 785-792. DOI: 10.17521/cjpe.2017.0314

戈壁针茅(Stipa tianschanica var. gobica)是多年 生旱生丛生小型草本, 属于针茅属(Stipa)羽针组 (Sect. Smirnovia), 广泛分布于内蒙古、宁夏与甘肃, 在河北、山西、陕西、新疆、青海、西藏也有分布, 在蒙古国主要分布于戈壁阿尔泰省, 是干旱区山地 砾石生草原的建群种(中国科学院内蒙古宁夏综合 考察队, 1985; 陈灵芝等, 2014)。戈壁针茅草原在我 国境内主要分布在内蒙古高原典型草原、荒漠草原 和荒漠区地带的山地(蛮汗山、大青山、乌拉山、狼 山、贺兰山、雅布赖山、河西走廊北山、祁连山、 马䦊山和天山东部)和石质丘陵顶部; 它的出现总 是与石质的原始粗骨性土壤有着密切联系, 向北主 要出现在蒙古国的东蒙古地区、戈壁阿尔泰山东段 山地和杭爱山区, 再向西只出现在戈壁区的北部 (李博, 1962; 内蒙古植物志编辑委员会, 1998; 陈灵 芝等, 2014)。因此, 从植物区系地理学上可以把戈 壁针茅定义为亚洲中部分布种。

群落生态学文献很少见基础样方数据, 严重限 制了研究成果的应用(张维康等, 2013), 群落调查的 样方资料是研究群落特征的重要依据, 也为植物群 落动态变化规律和植被志等植被专著编研提供了重 要基础数据(杨瑶等, 2014; 乔鲜果等, 2017)。科学、 准确而又详尽的植物群落样方数据是植被生态学研 究的基础, 也是生态学其他领域的重要参考资料。 戈壁针茅与石生针茅(Stipa tianschanica var. klemenzii) 在形态学特征上十分相似, 生态特征及对生境 的适应性上也较为相似, 两者常混生, 而石生针茅 草原在蒙古高原荒漠草原区生态幅较宽, 分布极广 泛, 常被作为荒漠草原植被的代表群落和景观类型 (中国科学院内蒙古宁夏综合考察队, 1985)。然而, 由于对戈壁针茅和石生针茅在形态上和分布生境特 征上认识的混乱, 导致《中国植被》(1980)、《内蒙 古植被》(1985) 以及《中华人民共和国植被图 1:1000000》(中国科学院中国植被图编辑委员会, 2007)中对于戈壁针茅草原和石生针茅草原的编写
出现了错误, 所描述的戈壁针茅草原特征实际是石 生针茅草原的特征, 而石生针茅草原的相关描述则 是戈壁针茅草原的内容。乔鲜果等(2017)已经对中 国石生针茅草原的分布、群落特征和分类进行了较 为详细的研究, 本文基于2005-2016年戈壁针茅草 原生长季的115个样地的群落调查数据, 系统分析 了中国戈壁针茅草原植物群落基本特征及其地理分 布, 进一步对中国戈壁针茅草原的群落特征进行研 究, 以达到彻底区分两类草原的目的, 同时为《中国 植被志》的编研提供基础数据和资料。

\section{1 研究方法}

\section{1 样地及样方调查}

植被考察于 2005年6月至2016年7月期间进行， 考察范围包括内蒙古高原温带草原区域的东部草原 亚区域中西部、黄土高原北部石质丘陵区域、天山 山脉东部、贺兰山、罗山等地。行政区域包括内蒙 古自治区乌兰察布市、呼和浩特市、包头市、鄂尔 多斯市、巴彦淖尔市、阿拉善盟, 河北省北部, 山西 省北部, 陕西省榆林市, 宁夏回族自治区中北部, 甘肃省全境, 青海省海南藏族自治州, 西藏阿里地 区札达县, 新疆维吾尔自治区哈密市。群落调查以 沿途路线的典型群落样地调查为主, 并结合对非典 型植物群落类型定位记录的方法。每个草本群落样 地设置 3 个 $1 \mathrm{~m} \times 1 \mathrm{~m}$ 的样方, 每个灌木群落样地设 置 1 个 $5 \mathrm{~m} \times 5 \mathrm{~m}$ 的样方, 灌木群落下设置 3 个 $1 \mathrm{~m} \times$ $1 \mathrm{~m}$ 的草本样方; 首先用手持GPS记录调查样地的 经纬度坐标、海拔高度及地形地貌特征、土壤类型 等, 然后记录所选典型戈壁针茅草原样地内所有的 物种, 及每个物种的高度、盖度、株(丛)数(密度), 并 齐地面剪取样方内所有物种的地上生物量, 带回实 验室在 $65{ }^{\circ} \mathrm{C}$ 烘箱条件下烘干至恒质量并称量。共调 查了 115 个戈壁针茅典型群落样地。

\section{2 数据处理及分析}

物种的区系地理成分、水分生态类型、群落物 
种组成、生活型以中国戈壁针茅草原所有样地内出 现的物种作为统计数据; 群落内物种丰富度、重要 值、物种盖度等级和恒有度等级划分以样方内记录 的所有物种作为统计数据。记录到的所有植物的生 活型通过查阅《Flora of China》(Wu et al., 2006)并 结合野外观察确定。物种的区系地理成分及水分生 态类型通过查阅资料(赵一之, 2012; 中国科学院内 蒙古宁夏综合考察队, 1985)和分析其分布区确定。 根据获取的资料, 对戈壁针茅草原的分布、生态特 征及群落特征(物种组成、生活型、区系地理成分、 盖度等级、恒有度等级及群落的数量特征)进行全面 的总结分析, 其中生活型、盖度等级、恒有度等级 的划分参考《数量生态学》(张金屯, 2011), 按照 Domin的盖度等级划分为 5 级, 1 级盖度级 $0-0.1 \% 、 2$ 级盖度级 $0.1 \%-1 \%$ 、3级盖度级 $1 \%-4 \%$ 、4级盖度级 $5 \%-10 \%$ 、 5 级盖度级 $11 \%-25 \%$; 恒有度等级划分为 I-V级：I级恒有度0-20\%, II级恒有度 $20 \%-40 \%$, III 级恒有度 $40 \%-60 \%, \mathrm{IV}$ 级恒有度 $60 \%-80 \%, \mathrm{~V}$ 级恒 有度 $80 \%-100 \%$ 。物种丰富度以样地的物种数(S)代 表; 重要值 $=($ 相对生物量 + 相对盖度 + 相对高度 $) / 3$ (方精云等, 2009)。根据群落的建群种和优势种, 并 考虑其生活型, 将调查到的戈壁针茅草原进一步划 分到群从组和群从(中国植被编辑委员会, 1980; 中 国科学院内蒙古宁夏综合考察队, 1985; 陈灵芝等, 2014)。

\section{2 结果}

\section{1 中国戈壁针茅草原的地理分布}

中国戈壁针茅草原主要分布于蒙古高原荒漠草 原区、典型草原区和荒漠区的山地。向南可以沿着 干燥的砾石质低山、丘陵分布到黄土高原北部地区 及燕山北部山地, 向西可以分布到新疆阿尔泰山和 东天山, 向西南可以分布到青海祁连山、柴达木盆 地、黄河流域丘陵山地和西藏西喜马拉雅地区。

\section{2 中国戈壁针茅草原的群落特征}

115 个样地的经度、纬度、海拔、群落盖度、群 落物种丰富度列于附录表 1 ; 每个样地上记录的 3 个 草本样方的平均值, 包括物种的高度、盖度、地上 生物量以及计算得到的重要值列于附录表2; 每个 样地的群落物种组成和各个物种的生活型、区系地 理成分及每个物种的盖度、恒有度列于附录表3; 将 所有样地的群落类型划分为 8 个群从组、 105 个群丛,
列于附录表4。

\subsection{1 物种组成及其生活型和水分生态类型}

调查样地共记录到维管植物 272 种, 其中裸子 植物 1 科 1 属 3 种, 被子植物 37 科126属269种, 包括单 子叶植物 4 科 30 属 71 种; 双子叶植物 33 科 96 属 198 种 (附录表3)。菊科为第一大科, 共52种植物, 主要为 一些矮小的多年生杂类草, 如阿尔泰狗娃花(Aster altaicus)、火线草(Leontopodium leontopodioides)、 小红菊(Chrysanthemum chanetii)、驴欺口(Echinops latifolius)、蒲公英(Taraxacum mongolicum); 一年生 草本有紊蒿(Elachanthemum intricatum)、黄花蒿 (Artemisia annua); 小半灌木有著状亚菊 (Ajania achilleoides), 半灌木有细裂叶莲蒿 (Artemisia gmelinii)、裂叶蒿(Artemisia tanacetifolia); 菊科植物 多为常见的伴生种, 其中萻状亚菊、华北米高 (Artemisia giraldii)、白莲蒿、柔毛蒿(Artemisia pubescens)可作为次优种与戈壁针茅形成群从。第二大 科为禾本科, 共 47 种植物, 以多年生丛生禾草为主, 其中针茅属植物有 9 种, 石生针茅、长芒草(Stipa bungeana)、西北针茅(Stipa sareptana var. krylovii)、 短花针茅(Stipa breviflora) 和沙生针茅 (Stipa caucasica subsp. Glareosa)均可作为共建种或次优种与 戈壁针茅形成群从。第三大科为豆科, 有38种植物, 多为矮小、铺散或垫状多年生草本, 以棘豆属 (Oxytropis) 、黄耆属 (Astragalus) 和锦鸡儿属 (Caragana)植物为主, 常见有囊墓棘豆(Oxytropis sacciformis)、薄叶棘豆(Oxytropis leptophylla)、多叶 棘豆(Oxytropis myriophylla)、乳白花黄耆(Astragalus galactites)和粘叶黄耆(Astragalus scaberrimus), 灌 木和小半灌木有小叶锦鸡儿 (Caragana microphylla)、狭叶锦鸡儿(Caragana stenophylla)和猫头刺 (Oxytropis aciphylla)。蓄薇科有4属16种植物, 多为 一些矮小的多年生草本, 以委陵菜属(Potentilla)为 主。百合科有 3 属 14 种植物, 以苞属(Allium)最为常 见, 其中砂非(Allium bidentatum)、细叶韭(Allium tenuissimum)、碱韭(Allium polyrhizum)及贺兰韭 (Allium eduardii)可作为次优种与戈壁针茅形成群 从莎草科植物有薹草属(Carex)和嵩草属(Kobresia) 植物共6种植物, 其中柄状蕚草(Carex pediformis)和 黄囊薹草(Carex korshinskii)为常见的亚优势种, 与 戈壁针茅形成群从。其他常见的植物还有: 石竹科 的细叶石头花 (Gypsophila licentiana)、瑞香科 
(Thymelaeaceae)的狼毒(Stellera chamaejasme)、旋花 科 (Convolvulaceae) 的银灰旋花 (Convolvulus ammannii)、藜科 (Chenopodiaceae) 的猪毛菜 (Salsola collina)、景天科(Crassulaceae) 的瓦松 (Orostachys fimbriata)、远志科 (Polygalaceae) 的细叶远志 (Polygala tenuifolia)等。

按照Raunkiaer的生活型分类法将戈壁针茅草 原的272种植物分为5种生活型(图1)。其中地面芽植 物占绝对优势, 占植物种数的 $65.44 \%$, 主要为多年 生丛生禾草和多年生杂类草, 反映了分布区冷季较 长; 地上芽植物占植物种数的 $14.34 \%$, 主要为一些 矮小、垫状的灌木、半灌木; 一年生植物占植物种 数的 $11.03 \%$, 仅次于地面芽和地上芽植物, 说明戈 壁针茅草原多处于气候干旱区; 地下芽植物占植物 种数的 $8.09 \%$, 主要为一些具根茎或鳞茎的植物; 高位芽植物均为灌木, 仅占植物种数的 $1.10 \%$ 。一些 植物在形态结构方面也表现出适应草原地区干旱、 少雨、多风等恶劣环境条件的特征: 如旱生灌木、 小半灌木的锦鸡儿属植物、猫头刺、耧斗叶绣线菊 (Spiraea aquilegiifolia)等的叶多深裂或退化成刺, 植株被毛, 气孔下陷以减少水分蒸发; 多年生旱生 草本针茅属植物为须根丛生, 地上枝条形成分蓝, 密集成从有利于根系更好地吸收土壤水分; 鳞茎草 本百合属植物山丹(Lilium pumilum)等, 具有明显的 地下鳞茎, 更新芽生于地下鳞茎节上, 有利于度过 不利环境。

根据《Flora of China》及《内蒙古维管植物分 类及其区系生态地理分布》, 将中国戈壁针茅草原 所有物种划分为 5 种水分生态类型(图2), 其中早生

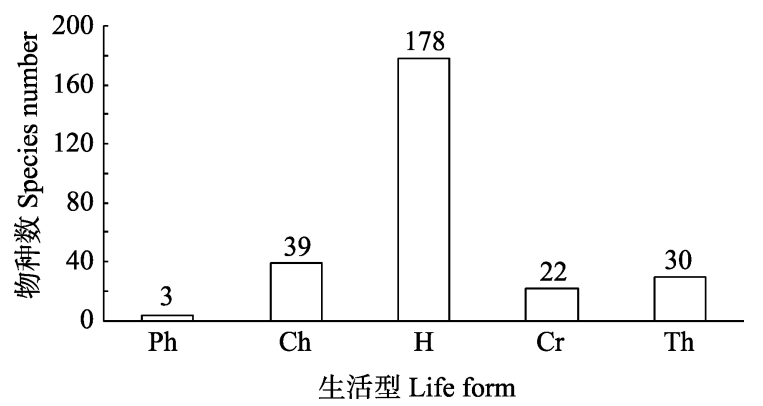

图1 戈壁针茅草原物种的Raunkiaer生活型谱。Ch, 地上芽 植物; Cr, 地下芽(隐芽)植物; H, 地面芽植物; Ph, 高位芽植 物; Th, 一年生植物。

Fig. 1 Raunkiaer's life form spectrum of the species in Stipa tianschanica var. gobica steppe. Ch, chamaephytes; Cr, cryptophytes; H, hemicryptophytes; Ph, phanerophytes; Th, therophytes.
植物最多，占总种数的 $44.12 \%$; 中旱生植物占总种 数的 $19.49 \%$; 中生植物占总种数的 $15.81 \%$; 旱中生 植物占总种数的 $11.76 \%$; 强早生植物占 $8.82 \%$ 。强旱 生植物与旱生植物共 144 种, 占总种数的 $52.94 \%$, 进一步说明戈壁针茅草原主要处在荒漠草原区, 气 候较为干旱。

\subsection{2 物种的区系地理成分}

通过查阅相关文献及对物种分布区的分析, 将 115 个调查样方内的 272 种植物划分为 9 种区系地理 成分 (图 3; 附录表 3), 东古北极成分最多, 占 $31.99 \%$, 如二裂委陵菜(Potentilla bifurca)、山蚂蚱 草(Silene jenisseensis)、瓣荵唐松草(Thalictrum petaloideum)、兴安胡枝子(Lespedeza davurica)、狼 毒、达乌里秦艽(Gentiana dahurica)等; 仅次于东古 北极成分的是亚洲中部成分，占30.88\%，如克氏针

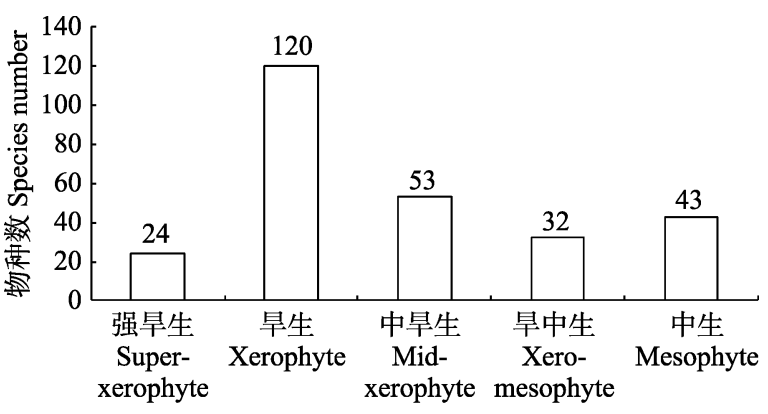

植物水分生态类型 Plant water ecotypes

图2 戈壁针茅草原物种的水分生态类型。

Fig. 2 Plant water ecotypes of the species in Stipa tianschanica var. gobica steppe.

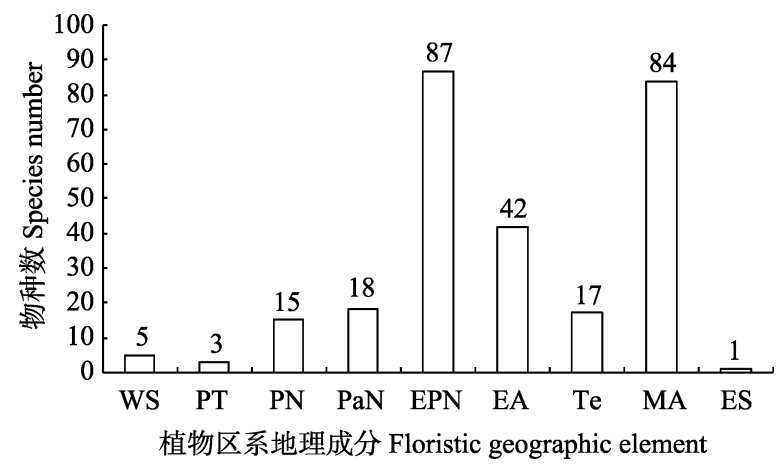

图3 戈壁针茅草原物种的区系地理成分分布。EA，东亚成 分; EPA，东古北极成分; ES，外来种; MA，亚洲中部成分; $\mathrm{PA}$, 古北极成分; PaA, 泛北极成分; PaT, 泛温带成分; PM, 古地中海成分; WS, 世界广布种。

Fig. 3 Floristic geographic distribution of the species in Stipa tianschanica var. gobica steppe. EA, East Asia element; EPA, East Palaeo-Arctic element; ES, exotic species element; MA, Middle Asia element; PA, Palaeo-Arctic element; PaA, Pan-Arctic element; PaT, Pan-Temeperate element; PM, Palaeo-Mediterranean element; WS, wide spread element. 
茅、短花针茅、伏毛山莓草(Sibbaldia adpressa)等, 充分反映出戈壁针茅草原作为欧亚草原植物区亚洲 中部亚区的一种重要草原类型, 其群落物种区系地 理成分组成上与欧亚草原区植被的密切联系; 东亚 成分占15.44\%, 如小红菊、硬质早熟禾(Poa sphondylodes)、知母(Anemarrhena asphodeloides)等, 这充 分说明了东亚植物区系与蒙古草原植物区系之间的 联系; 古北极成分占 $6.62 \%$, 如驼线藜 (Krascheninnikovia ceratoides)、华北岩黄耆(Hedysarum gmelinii)、地锦(Euphorbia humifusa)等; 古地中海成分占 $6.25 \%$, 如刺沙蓬(Salsola tragus)、木地肤(Kochia prostrata)、白草(Pennisetum centrasiaticum)等, 反映 了干旱荒漠区对戈壁针茅草原有着一定的影响; 泛 北极成分占5.51\%, 如猪毛菜、冷蒿(A. frigida)、裂 叶蒿等; 世界分布种占 $1.84 \%$, 有藜(Chenopodium album)、鹅线委陵菜(P. anserina)、画眉草(Eragrostis pilosa)、狗尾草(Setaria viridis)等; 泛温带成分只有 三芒草(Aristida adscensionis)、小画眉草(Eragrostis minor)和教藜(Tribulus terrester), 占 $1.1 \%$; 还有 1 种 外来种, 即紫花苜宿(Medicago sativa)。植物区系地 理成分的多样性表明戈壁针茅的广泛传播和对生境 的适应性, 相比于石生针茅草原(乔鲜果等, 2017), 戈壁针茅草原的区系地理成分中, 东古北极成分所 占比例略高于亚洲中部成分, 这是两类草原的区别 之处。

\subsection{3 群落的数量特征}

戈壁针茅草原的物种组成变化相对较大, 基于 115 个样地的统计, 群落盖度一般集中在 $10 \%-20 \%$ 之间, 将戈壁针茅草原群落样方内 272 种植物的盖 度(各个样地的平均值), 按照Domin的盖度等级划 分为 5 级 (图4): 盖度等级多为 1 级和 2 级, 其中 1 级盖 度的植物多为偶见种或伴生种, 占样方内物种总数 的 $24.26 \%$; 2 级盖度的植物多为常见的伴生种, 占样 方内物种总数的 $63.97 \%$; 二者共占所有植物种数的 88.23\%。3级盖度的植物多为群落中的草本层片次 优种或群落的亚建群种, 与戈壁针茅共同构建群落, 占样方内物种总数的 $11.4 \% ; 4$ 级盖度的植物为 $0 ; 5$ 级盖度 $(11 \%-25 \%)$ 的植物仅建群种戈壁针茅1种。将 戈壁针茅草原样方内 272 种植物各自在样地中出现 的次数占所有样地数的百分比, 按照恒有度等级划 分为 I-V级(图5): I级恒有度植物占所有植物种数的 94.85\%, 多为偶见种或不常见伴生种; II级恒有度
植物占 $4.03 \%$, 多为常见的伴生种; III级恒有度植物 占 $1.04 \%$, 均为常见的伴生种; 无IV级恒有度植物; $\mathrm{V}$ 级恒有度植物仅建群种戈壁针茅1种。

\section{3 戈壁针茅草原植被类型的划分}

戈壁针茅草原是石质化荒漠草原的群落类型, 多零星分布在草原区山地基岩露出的砾石质坡地上, 群落类型因次优势种和伴生种层片的性质不同而分 化出多种群从。本文基于群落调查数据, 按照植物 群落分类原则(中国植被编辑委员会, 1980), 根据共 建群种或次优势种, 并结合其生活型及群落数量特 征(盖度、高度、生物量), 系统地将戈壁针茅草原群 系以下的单位进一步划分为 8 个群从组 106 个群从 (附录表4):

1)戈壁针茅-禾草群从组Ass. Group Stipa tianschanica var. gobica-bunch grass

主要由戈壁针茅与短花针茅、石生针茅、西北 针茅、中亚细柄茅(Ptilagrostis pelliotii)等几种较为 高大的从生禾草为亚优势成分组成的群从构成, 主 要见于内蒙古大青山、乌拉山、雅布赖山石质山坡 及山前丘陵, 乌兰察布高原的石质丘陵, 陕西神木 的黄土硬梁，甘肃兰州永登县东北山坡坡顶等地。

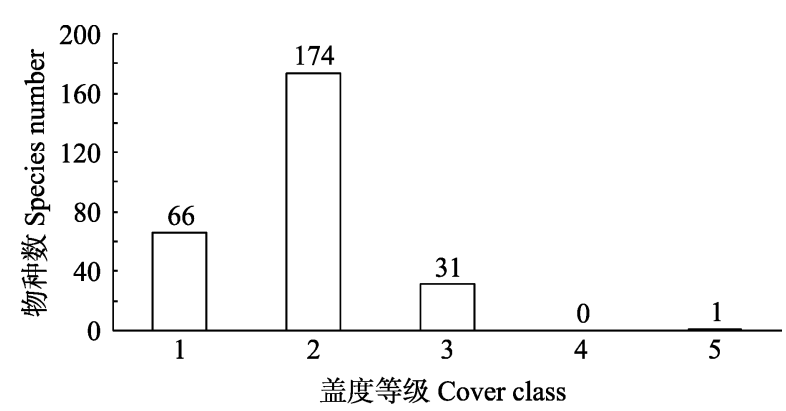

图4 戈壁针茅草原物种的Domin盖度等级分布。

Fig. 4 Domin's cover class distribution of the species in Stipa tianschanica var. gobica steppe.

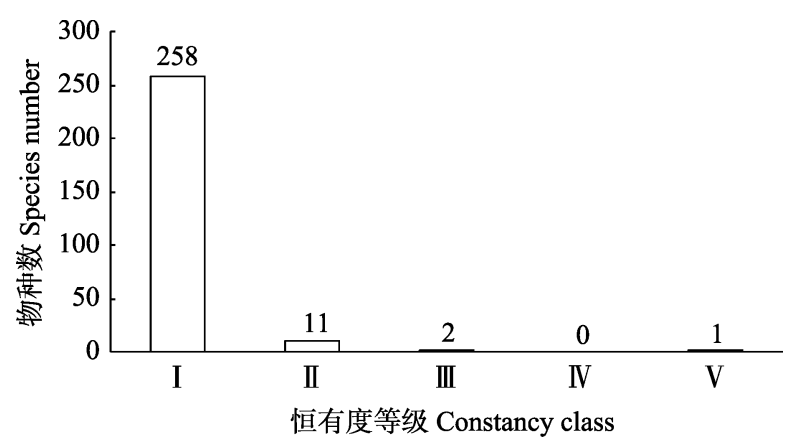

图5 戈壁针茅草原物种的恒有度等级分布。

Fig. 5 Constancy degree distribution of the species in Stipa tianschanica var. gobica steppe. 
2)戈壁针茅-小禾草群丛组 Ass. Group Stipa tianschanica var. gobica-smail bunch grass

主要由戈壁针茅与冰草(Agropyron cristatum)、 无芒隐子草(Cleistogenes songorica)、丛生隐子草 (Cleistogenes caespitosa)、白羊草(Bothriochloa ischaemum)和沙生冰草(Agropyron desertorum)等丛生 小禾草为优势成分的群丛构成, 其中以冰草和隐子 草属植物在群落中作用最大, 主要见于内蒙古鄂尔 多斯西部桌子山、大青山石质山坡及山前丘陵区, 察哈尔右翼后旗的乌兰哈达火山堆坡顶处, 甘肃省 武威市西祁连山北麓以及河北省张家口市东南翠云 山西端等处。

3)戈壁针茅-臺草群丛组Ass. Group Stipa tianschanica var. gobica-Carex spp.

主要指戈壁针茅群落中亚优势层片的优势成分 为薹草属一些物种的群丛, 主要有黄囊薹草、柄状 臺草、干生臺草(Carex aridula)等, 其中尤以干生臺 草为亚优势种的群从在本群从组中为多。臺草多不 耐强光照环境, 因此本群从组多分布在林下边缘的 石质山坡。分布区主要在内蒙古鄂尔多斯市准格尔 旗黄土丘陵区神山林场砾质山坡、包头市西北方向 乌拉山主峰大桦背山顶石质山坡、山西大同市吕梁 山北端山前石质丘陵、河北省张家口市东南翠云山 西端山前石质丘陵等地。群落中常见百里香(Thymus mongolicus)、砂非、石生齿缘草(Eritrichium rupestre)、线果芹(Eriocycla albescens)、长叶点地梅(Androsace longifolia)等。相比于蒙古高原典型的荒漠草 原戈壁针茅群落, 此类群丛物种丰富度较高, 物种 组成更为丰富。

4)戈壁针茅-苾类群丛组Ass. Group Stipa tianschanica var. gobica-Allium spp.

组内各群从鳞茎草本层片优势成分主要集中在 细叶韭、砂韭、碱非、矮非(A. anisopodium)、贺兰 韭等物种上, 其中影响较大的以碱韭、砂非和细叶 非为最明显, 碱非又称多根葱, 耐盐碱性能力较强, 砂韭和细叶韭相比其他种类耐干旱能力较强。

5)戈壁针茅-杂类草群从组Ass. Group Stipa tianschanica var. gobica-forbs

主要指由戈壁针茅与细叶石头花、细叶远志、 细茎黄鹤菜(Youngia tenuicaulis)、银灰旋花、达乌 里芯芭(Cymbaria dahurica)等一些轴根型的多年生 杂类草作为亚优势成分所组成的群丛, 这些群从内
每平方米物种饱和度在 2-21种之间, 盖度变化在 8\%-52.5\%之间，因群丛生境的不同而呈现出较大 的差异。

6)戈壁针茅-一二年生草本群丛组Ass. Group Stipa tianschanica var. gobica-annual-biennial herb

群从内亚优势层片为一、二年生草本层片, 这 些植物多为短命植物, 以猪毛菜、刺沙蓬、狗尾草、 地蓄微(Chamaerhodos erecta) 最为常见, 其他层片 多为杂类草层片, 灌木、小半灌木层片及丛生小禾 草层片, 分布区多集中在内蒙古巴彦淖尔市乌拉特 后旗狼山北部山前石质丘陵、宁夏银川市贺兰山南 段东侧石质半阳坡等极端干旱区域。

7)戈壁针茅-小半灌木群丛组Ass. Group Stipa tianschanica var. gobica-semi shrub

是适应于特定基质条件所发生的群落类型, 地 面的剥蚀和表层土壤的侵蚀加重以及人为活动(放 牧)等的影响是演替形成这一群落类型的重要生态 因素, 群从中的小半灌木层片分别以百里香、著状 亚菊、灌木亚菊(Ajania fruticulosa)、蒙古获(Caryopteris mongholica)、兴安胡枝子、岩蒿(Artemisia rupestris)、白莲蒿等占优势, 主要在内蒙古阿拉善 盟雅布赖山东端石质山坡的阳坡、乌兰察布市四子 王旗葛根塔拉草原石质丘陵及宁夏银川市贺兰山北 端石质半阳坡等处。

8)灌丛化戈壁针茅群丛组Ass. Group Stipa tianschanica var. gobica-undershrub

属于前述各类戈壁针茅草原群落的砾石质土壤 的生态变体, 由于土壤机械组成成分的变粗, 砂质、 砂砾质、砾石质比重的增加, 改善了土壤的通气状 况和水分营养状况, 为灌木植物的渗入和扩展创造 了有利条件, 因而在干旱的气候条件下形成旱生丛 生禾草层片和深根系的耐旱灌木层片相结合的特殊 群落结构, 这类灌从主要以小叶金露梅(Potentilla parvifolia)、中麻黄(Ephedra intermedia)和荒漠锦鸡 儿 (Caragana roborovskyi) 和松叶猪毛菜 (Salsola laricifolia)为主, 分布区在内蒙古巴彦淖尔市狼山 南部山前石质丘陵、甘肃省肃北县马鬃山石质阳坡 和内蒙古鄂尔多斯市桌子山中部石质山坡的阳坡。

\section{3 结论和讨论}

戈壁针茅草原是分散分布在草原区以及荒漠区 的石质丘陵与低山上部的一个群落类型, 群落组成 
中常伴有喜砾石的草本、半灌木和小半灌木, 其物 种的科属组成相比石生针茅草原较复杂, 记录到维 管植物38科127属272种, 水分生态类型、生活型组 成相对简单, 区系地理成分组成复杂, 既显示了其 分布中心蒙古高原草原的特殊性, 又体现出其砾石 质化较为严重的生境的独特性。盖度等级和恒有度 等级偏低, 在一定程度上说明组成戈壁针茅群落的 物种生长不均匀, 群落间变异较大, 群落结构简单, 物种盖度、地上生物量偏低, 也是植物生存环境条 件较差的反映, 这主要是受戈壁针茅群落分布特点 和特殊的生境制约形成的。戈壁针茅草原虽然在荒 漠草原区分布较集中, 但在典型草原区和荒漠区的 适宜生境中也常能形成优势群落, 所以群落地理分 布跨度大, 在不同的区域中除建群种外, 优势种和 常见伴生种差异较大, 整个群系中物种的恒有度等 级偏低; 另外, 戈壁针茅草原群落的出现总是与石 质的原始粗骨性土壤保持密切的联系, 总是分布于 石质丘陵或山地, 环境条件相对较差, 同时群落不 会向石生针茅群落那样在层状高平原上有大面积、 连续的分布, 所以使得群落间变异较大、群落结构 简单、盖度偏小, 致使群落中物种盖度等级也偏小。

在分布区范围内, 戈壁针茅除了作为建群种形 成独立戈壁针茅群落外, 还经常出现在其他禾草、 杂类草草原, 如短花针茅群落、石生针茅群落、甘 青针茅(Stipa przewalskyi)群落、羊草(Leymus chinensis)群落等; 在内蒙古我们还发现戈壁针茅也常 出现在白莲蒿、百里香、萻状亚菊等旱生小半灌木 群落当中, 对山地生态条件的适应性比较广泛; 受 山体所处地带的影响, 戈壁针茅草原的群落组成也 具有明显的地带性烙印, 但由于山地生境条件的特 殊性, 群落中适应岩缝砾质土环境的植物居多数, 一些植物具有莲座状形态(如瓦松), 从生和匍生形 态也很普遍; 群落结构的不均匀性十分明显, 而且 一般情况下戈壁针茅草原并不占有很大的面积, 多 以片段形式出现, 并和其他的石生植物群落(以地 衣为主)、石缝植物群落结合在一起。

本研究发现戈壁针茅草原在蒙古高原和黄土高 原北部的适宜生境中分布较为广泛, 特别是内蒙古 地区更为突出; 在蒙古高原的北部, 即蒙古国境内, 戈壁针茅群落主要分布在中部和南部的适宜地区, 如戈壁阿尔泰山以及东戈壁的石质丘陵上, 但分布 面积没有中国境内广泛; 在蒙古国西北部地区, 如
杭爱山西部、大湖盆地区、准噶尔戈壁地区的石质 山坡、丘陵上的相似生境中, 逐渐被东方针茅(Stipa orientalis)草原群落占据, 局部地段有镰芒针茅 (Stipa caucasica)草原分布。内蒙古地区有广泛分布 的戈壁针茅草原群落, 是因为其中部有东西跨度 $1200 \mathrm{~km}$ 的阴山山地, 同时在阴山北边有一条西起 巴彦淖尔市乌拉特中旗东到锡林郭勒盟镶黄旗的花 岗岩丘陵; 此外分布于草原区的熔岩台地, 以及分 布于于荒漠区的石质山地、丘陵(如贺兰山、巴彦乌 拉山、巴彦诺尔公丘陵、曼德拉山、雅布赖山、河 西走廊北山等)都是适合戈壁针茅群落分布的生境。

戈壁针茅草原的生境多限于石质山坡、丘陵顶 部, 所以群落面积没有相近的短花针茅草原、石生 针茅草原大, 但其群落生态特征鲜明, 是中国北方 干旱区和半干旱区重要的草原类型和放牧场。本研 究是在已有研究的基础上, 尽可能地对戈壁针茅草 原分布区的群从作了实地调查基础上完成的, 但受 多种条件的限制, 可能还有部分群从类型没有调查 到, 对中国戈壁针茅草原某些数量特征、生态特征 等方面的分析和描述也有所欠缺, 还有待于进一步 全面系统的调查研究。

针茅属植物是一类高度适应半干旱气候的类群, 在形态上有些种类差别很小, 所以在分类学上常常 被处理为种下单位。但是它们之间有差别的形态性 状是稳定而不连续的, 且地理分布中心是不一致的, 另外其作为建群种所形成的群落的环境特征差异显 著且群落分布中心也不一致; 这样的种类在针茅属 中有戈壁针茅(Stipa tianschanica var. gobica = Stipa gobica)、石生针茅(Stipa tianschanica var. klemenzii = Stipa klemenzii)、西北针茅(Stipa sareptana var. krylovii = Stipa krylovii)等。戈壁针茅和天山针茅形态 区别参见Nobis (2014)的研究, 按照形态-地理学和 生态学物种的概念, 戈壁针茅是应该按照独立的种 来处理的, 其学名为Stipa gobica Roshev.。

\section{参考文献}

Chen LZ, Sun H, Guo K (2014). Floristic and Vegetation Geography of China. Science Press, Beijing. 469-500. [陈灵 芝, 孙航, 郭柯 (2014). 中国植物区系和植被地理. 科 学出版社, 北京. 469-500.]

Editorial Board of the Flora of Nei Mongol (1998). Flora of Nei Mongol (Tomus 1). 2nd edn. Nei Mongol People's Publishing House, Huhhot. 78-81. [内蒙古植物志编辑委员 会 (1998). 内蒙古植物志(第一卷). 第二版. 内蒙古人 
民出版社，呼和浩特. 78-81.]

Comprehensive Expedition in Nei Mongol, Ningxia, Chinese Academy of Sciences (1985). Nei Mongol Vegetation. Science Press, Beijing. [中国科学院内蒙古宁夏综合考 察队 (1985). 内蒙古植被. 科学出版社, 北京.]

Editorial Board of the Vegetation of China (1980). Vegetation of China. Science Press, Beijing. [中国植被编辑委员会 (1980). 中国植被. 科学出版社, 北京.]

Fang JY, Wang XP, Shen ZH, Tang ZY, He JS, Yu D, Jiang Y, Wang ZH, Zheng CY, Zhu JL, Guo ZD (2009). Methods and protocols for plant community inventory. Biodiversity Science, 17，533-548. [方精云, 王襄平, 沈泽昊, 唐志 尧, 贺金生, 于丹, 江源, 王志恒, 郑成洋, 朱江玲, 郭 兆迪 (2009). 植物群落清查的主要内容、方法和技术规 范. 生物多样性, 17, 533-548.]

Li B (1962). The basic types of the zonal vegetation in Inner Mongolia and its ecological geographic rule. Journal of Inner Mongolia University (Natural Sciences Edition), 4, 41-71. [李博 (1962). 内蒙古地带性植被的基本类型及 其生态地理规律. 内蒙古大学学报(自然科学版), 4, 41-71.]

Nobis M (2014). Taxonomic revision of the central Asian Stipa tianschanica complex (poaceae) with particular reference to the epidermal micromorphology of the lemma. Folia Geobot, 49, 283-308.

Qiao XG, Guo K, Zhao LQ, Liu CC, Zhao HW, Hou DJ, Gao CG (2017). Distribution, community characteristics and classification of Stipa tianschanica var. klemenzii steppe in China. Chinese Journal of Plant Ecology, 41, 231-237. [乔鲜果，郭柯，赵利清，刘长成，赵海卫, 侯东杰，高 趁光 (2017). 中国石生针茅草原的分布、群落特征和分
类. 植物生态学报, 41, 231-237.]

The Editorial Committee of Vegetation Map of China, Chinese Academy of Sciences (2007). Vegetation Map of the People's Republic of China 1:1000000. Geological Publishing House, Beijing. [中国科学院中国植被图编辑委员会 (2007). 中华人民共和国植被图1:1000000. 地质出版 社, 北京.]

Wu ZY, Raven PH, Hong DY (2006). Flora of China. Tomus 22. Science Press, Beijing; Missouri Botanical Garden, St. Louis.

Yang Y, Guo K, Zhao LQ, Zhao HW, Qiao XG, Liu HM, Liu CC (2014). Community characteristics of Stipa roborowskyi steppe in Xizang. Chinese Journal of Plant Ecology, 38, 635-639. [杨瑶, 郭柯, 赵利清, 赵海卫, 乔 鲜果, 刘慧明, 刘长成 (2014). 西藏昆仑针茅草原的基 本特征. 植物生态学报, 38, 635-639.]

Zhang JT (2011). Quantitative Ecology. Science Press, Beijing. [张金屯 (2011). 数量生态学. 科学出版社, 北京.]

Zhang WK, Li H, Wang GH (2013). Community characteristics of main vegetation types along two altitudinal transects on mountains of northwestern Beijing, China. Chinese Journal of Plant Ecology, 37, 566-570. [张维康, 李贺, 王国 宏 (2013). 北京西北部山地两个垂直样带内主要植被 类型的群落特征. 植物生态学报, 37, 566-570.]

Zhao YZ (2012). Classification and Its Floristic Ecological Geographic Distributions of Vascular Plants in Inner Mongolia. Inner Mongolia University Press, Huhhot. 1-856. [ 赵一之 (2012). 内蒙古维管植物分类及其区系 生态地理分布. 内蒙古大学出版社, 呼和浩特. 1-856.]

责任编委: 王德利 责任编辑: 李 敏

附录 中国戈壁针茅草原的分布、群落特征和分类

Supplement Distribution, community characteristics and classification of Stipa tianschanica var. gobica steppe in China http://www.plant-ecology.com/fileup/PDF/cjpe.2017.0314-D1.xls

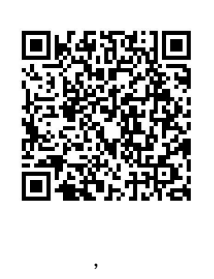

www.plant-ecology.com 